\title{
Cefuzonam Sodium
}

National Cancer Institute

\section{Source}

National Cancer Institute. Cefuzonam Sodium. NCI Thesaurus. Code C98232.

The sodium salt form of cefuzonam, an injectable, semi-synthetic, second-generation cephalosporin with broad-spectrum antibiotic activity. 